\title{
Exploration on Recognition and Construction of Core Competitiveness of Enterprise Culture \\ Qing Chen
}

\author{
Lanzhou University of Arts and Science, Lanzhou Gansu, 730000, China
}

\begin{abstract}
Key words: Enterprise culture, Core competitiveness, Recognition, Construction.
\end{abstract}
\begin{abstract}
. core competitiveness is the source for an enterprise to gain the sustainable competitive advantage and has become an important tool to analyze effective competition and growth of enterprises. This paper analyzes the features of core competitiveness and proposes several suggestions for Chinese private enterprises on recognition and construction of core competitiveness, in the hope of helping future development of enterprises.
\end{abstract}

\section{Introduction}

Introduction: how does an enterprise stand firm, make it big and string and always keep the competitive edge in the fierce operation environment? It has been a question that managers think over all the time. Besides, it is also a focus of academic circle. Core competence theory which has risen in recent years provides a new thought and method for our discussion. Core competitiveness was first proposed by Prahalad and Gamel. In the article Corporate Core Competitiveness which was published by them on Harvard Business Review in 1990, they defined core competitiveness as accumulative knowledge in an organization and especially the knowledge about how to coordinate different production skills and organically combine multiple skills. Later, many economists and managerialists enriched and developed this concept. Based on the existing research results, the author expounds his own understanding of core competitiveness and regards it as the basis of recognizing and constructing core competitiveness.

\section{Recognition of core competitiveness of enterprise culture}

\section{Recognition of core competitiveness of enterprise culture from the external}

Core competitiveness of enterprise culture may be recognized externally. There are three external standards to recognize core competitiveness of enterprise culture. The first one is economic benefit of an enterprise. Usually, core competitiveness of an enterprise refers to economic benefit of this enterprise. Survival and development of an enterprise are mainly judged according to the profitability of this enterprise. If the production efficiency and economic benefit of an enterprise are good, the core competitiveness of this enterprise is strong. On the contrary, if the production capacity of an enterprise falls behind the average level of the same industry and the economic benefit is poor, the core competitiveness of this enterprise is naturally weak[1].

Besides, the second standard to recognize core competitiveness of enterprise culture is market influence of an enterprise. The product or service quality of an enterprise, its reputation, development trend, development momentum, centripetal force, cohesive force and cultural level are the indexes to judge market influence of the enterprise. If an enterprise continues to provide high-quality products or services for the market, and continues to gain good reputation of users, the enterprise owns great potential development space. We can basically judge this enterprise has good market influence, occupy a dominant position in market competition and receives universal attention of the society. On 
the contrary, an enterprise is going downhill and fails to manage and operate well, and its cohesive force is weak. All these can be reflected from the decrease in the market influence.

The third standard is brand image of an enterprise. World advanced enterprises often own powerful brand image. For example, Microsoft has established a firm brand image in electronic computer field, while Apple Inc has successfully created a corporate image superior to other brands in the mobile phone field. Corporate image directly influences recognition degree of an enterprise in the market competition. The enterprises with favorable image often won the support and acceptance of more users. Brand image is usually a direct standard to recognize core competitiveness of enterprise culture[2].

It is necessary to notice that external recognition standards of core competitiveness of enterprise culture only have reference value, and they are mainly used to judge the competitive capacity of an enterprise in external market environment and fail to go deep into the operation field of an enterprise for overall review. Thus, external standards of core competitiveness of enterprise culture are too superficial and rough, and they do not own unassailable persuasion. Especially at the level of economic benefit evaluation, they lack the analysis from multiple perspectives. In addition, fine audit criteria are not used for calculation and estimation. Hence, we should not only apply external recognition standards during evaluating core competitiveness of enterprise culture, but also carry out further recognition work through going deep into the internal environment of the enterprise.

\section{Recognition of core competitiveness of enterprise culture from the internal}

Internal recognition standards of core competitiveness of enterprise culture are much more complex than external standards, and also own the features of comprehensiveness. Internal recognition standards can reflect the strength of core competitiveness more accurately, and the recognition result is scientific and convictive. There are mainly three internal standards. The first one is value addition recognition standard. Value addition recognition standard mainly refers to product and service quality in the production and operation process. Customer satisfaction is a direct standard to evaluate enterprise contribution to customers. If an enterprise continues to provide quantities of superior products and services for customers, customer satisfaction will continue to rise. We can judge the value addition is large of this enterprise and core competitiveness of enterprise culture is strong. If an enterprise judges its core competitiveness internally, it must depend on careful survey of customer group, and regard user satisfaction as the wind indicator guiding enterprise development. In this way, core competitiveness of the enterprise can improve stably ${ }^{[3]}$.

The second standard is advancement recognition standard. Advancement recognition standard can be embodied through specific numerical value, and it owns strong scientificity and accuracy. Advancement recognition standard is mainly used to judge the degree of keeping ahead of competitors in the same industry, i.e. to judge the position of the enterprise in the same industry. The enterprises with strong advancement often can strive for the best and occupy the important position in the same industry. On the contrary, the enterprises with poor advancement are usually in the disadvantageous position in the same industry. The core competitiveness of enterprise culture can be directly reflected from advancement recognition standard. The advancement recognition standard can be first reflected through financial indexes of an enterprise. The business performance of an enterprise can intensively reflect marker control force of the enterprise. Besides, excavation indexes of potential competitiveness can be used to judge advancement ability and core competitiveness of an enterprise. Although an enterprise which just starts up is insufficient in the scale and operation ability, if the enterprise culture and business operation own obvious advantages, they enterprise has large advancement possibility and good upside potential of core competitiveness. Moreover, management ability and innovation ability of an enterprise may also be regarded as potential advantage standards of an enterprise. In particular, innovation ability of an enterprise can make the enterprise occupy a dominant position in future market development. The enterprises with innovation ability will certainly stand out in future market competition. So, competition ability is an important standard to evaluate potential advancement of an enterprise. 
The third standard is core recognition standard. Core recognition standard comprehensively examines and evaluates core competitiveness of enterprise culture. Comprehensive indexes of an enterprise can be finally conformed through overall investigation of enterprise operation and development conditions. The core standards to evaluate core competitiveness of enterprise culture include the integrating capacity of an enterprise in resource allocation as well as knowledge and skill content in product production and service supply. Furthermore, keeping continuous management efficiency appreciation through resource integration and technology is a part of core competitiveness of an enterprise. An enterprise, based on existing resources, continues to expand and develop new businesses, which can reflect continuity ability of an enterprise in enterprise profit and development. It is also one of core indexes to evaluate core competitiveness of enterprise culture. The stronger resource integration ability and expansion continuity ability, the larger the core competitiveness. If the specific estimation value of enterprise integration and continuity ability is larger, core competitiveness of enterprise culture owns the better rising advantage ${ }^{[4]}$.

\section{Construction strategy for core competitiveness of enterprise culture}

\section{Internal strategy to construct core competitiveness of enterprise culture}

Core competitiveness of enterprise culture can also be constructed through internal reform and external expansion. Main factors influencing core competitiveness of enterprise culture are internal factors of an enterprise. Thus, during formulating the strategy to improve core competitiveness, an enterprise must carry out internal reform and optimization to improve core competitiveness. Firstly, the enterprise should reform and optimize the operating strategy. The enterprise operation directly influences economic benefit and profit of an enterprise. It is the foundation for long-term development of an enterprise. Therefore, the enterprise must thoroughly reform the defects in traditional operation mode, replan the layout of enterprise management strategy through modern business management and operation strategy and make the enterprise own stronger development power. An enterprise should improve internal resource integration capability, optimize organizational structure, establish a set of all-round, multi-level and comprehensive operation system, implement systematical integration of operation business units at different levels, coordinate different business units and different resource types and create a favorable internal environment for enterprise operation and development. In addition, it is also required to reform arrangement system of internal institutions, improve management level, establish right and responsibility implementation system by levels, enhancer overall control force through downsizing, merger and reduction of unnecessary structures, improve production and operation efficiency and coordinate human resource operation so as to implement improvement of comprehensive competitiveness of enterprise culture ${ }^{[5]}$.

Secondly, enterprises should apply continuity operating strategy, plan strategic development and layout with development view and facilitate sustainable development. Under the guidance of long-term development strategic deployment, enterprises should optimize resource allocation, make sure the resources can appreciate stably in the long-term project, avoid resource waste furthest, and adopt other continuity strategies to enhance potential competitiveness of enterprises. Enterprises should attach importance to keeping confidential to core technologies, coordinate internal interpersonal relationship, improve centripetal force, enhance maintenance of core technologies and core talents and keep the leading position in the same industry. Firstly, enterprises should strictly control use of special resources, set up special resource management department, strictly allocate and manage special resources in each link of enterprise production and operation and make sure special resources will not be revealed in the complex production process. Secondly, enterprises should enhance patent protection awareness, effectively maintain their patent right by legal means and avoid the disclosure of employees' efforts and wisdom to other competitors. Finally, enterprises also should continuously optimize and upgrade enterprise culture, create the innovative enterprise culture with core value, improve employees' sense of responsibility and centripetal force, maintain enterprise 
human resource, ensure long-term development and enhance core competitiveness of enterprise culture.

\section{External strategy to construct core competitiveness of enterprise culture}

Future market competition environment will be dominated by cooperation and competition. Enterprises cannot ignore the importance of cooperation in the fierce market competition. Only when enterprises complement each other's advantages can they gain more superior resources and broader development space in their development process. Thus, to improve core competitiveness, it is required to enhance enterprises' strategic alliance first. Enterprise need to confirm the alliance targets and objects according to short-term and long-term development strategy, and then formulate rational and operable alliance task planning so as to better guide implementation and operation of alliance work. During alliance cooperation, enterprises should keep equal and mutual help relation of alliance parties, and regard good faith as the alliance foundation so as to establish good alliance image and enhance core cultural competitiveness.

Finally, enterprises should expand their operation scale through continuous merger and acquisition to improvement of comprehensive competitiveness. Merger and acquisition strategy is the only way to achieve further improvement of core competitiveness after enterprises stably develop and expand. Competition and elimination coexist. If enterprises stand out in market competition, they can certainly form strategic surrounding of other competitors and make them become the service platform for the enterprises to further expand resource allocation and expand. Thus, except stably improving core competitiveness, enterprises should seize the key period of growth and development and apply merger and acquisition strategy to achieve qualitative leap of core competitiveness of enterprise culture so as to gain more market resources, further enhance market influence, make the enterprises become the outstanding ones in the same industry, optimize overall strategy layout of operation and development and open up a new way to improve core competitiveness of enterprise culture.

\section{Conclusions}

To effectively manage core competitiveness of Chinese enterprises, it is necessary to know the real connotation of core competitiveness and own clear and rational strategies. Enterprise senior leaders need to combine market environment to judge enterprise competitiveness, adopt core competitiveness to conceive the strategy, then internally audit enterprise operation business, resources and abilities, externally observe market demand and development trend of technology, apply innovation spirit to recognize the development direction of core competitiveness and choose different strategic direction in accordance with internal operation strategy, external trading strategy and different conditions.

\section{References}

[1] Xu Jianzhong, Zhu Meirong, Research on the Manufacturing Firms' Core Competency DNA Structure and Genetic Law in the View of Para-life. Journal of Business Economics, 2012(8):18-24.

[2] Wei Lin, Yao Shicong, Shi Yu et al., Effect of Cost Leadership Strategy for Enterprise Core Competitiveness - Evidence from the Listed Companies around Financial Crisis. Journal of Hebei University of Economics and Business, 2015(1):89-96.

[3] Wang Liping, Li Longxiao, Study on Effect of Environmental Regulation in the Core Competitiveness of Enterprises - Based on Panel Data of Pollution Intensive Industrial Enterprises. Resource Development \& Market, 2015,31(9):1105-1107.

[4] Hu Xiaoxian, Improvement of Enterprise Core Competitiveness Based on Enterprise Cultural Construction - Exploration of Important Effect of Enterprise Cultural Construction on 
Improvement of Enterprise Core Competitiveness under New situation. Enterprise Culture (II), 2016(6):3-3,6.

[5] Shen Aihua, Fan Cuiping, Li Baoquan et al., Countermeasures to Improve Core Competitiveness of Agricultural Technology Enterprises - Case Study of Jiangsu Mingtian Agriculture and Animal Husbandry Science \& Technology Co., Ltd.. Jiangsu Agricultural Sciences, 2015(8):475-476,477. 